\title{
الحماية الدولية للأدارة العامة في مواجهة ازمة الفساد الاداري
}

\author{
Doi: $10.23918 /$ ilic2021.11 \\ م. آلاء بهاء عمر \\ كلية القانون والعلاقات الدولية /جامعة بيان /اربيل \\ Alaa.bahaa@bnu.edu.iq
}

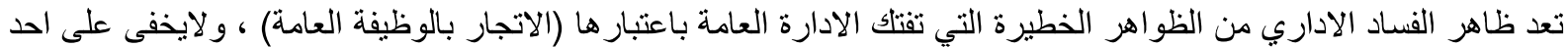

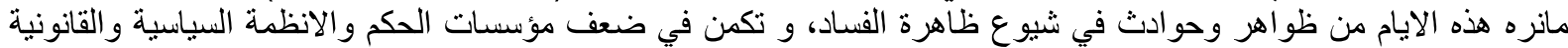

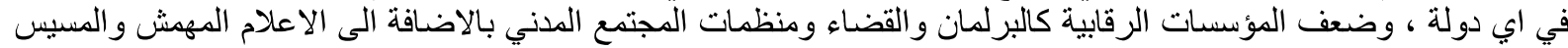

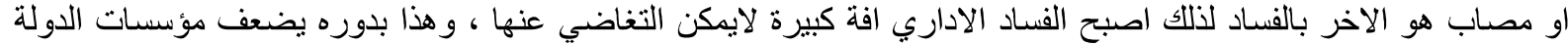

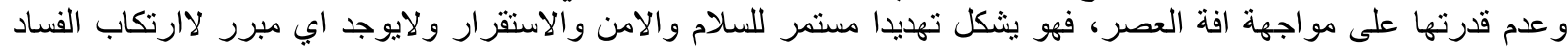

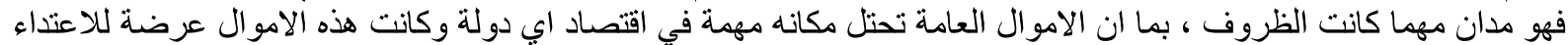

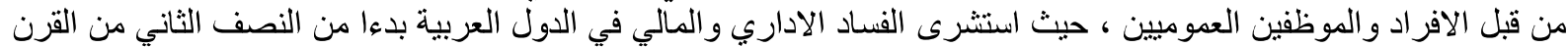

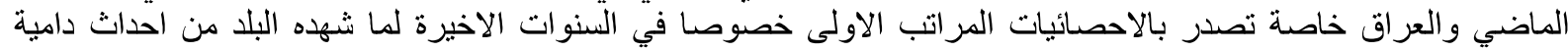

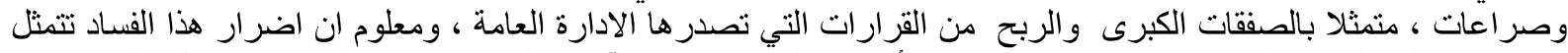

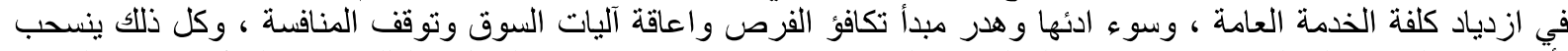

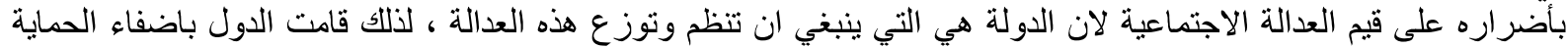

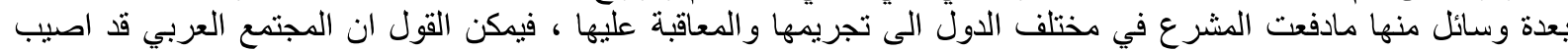

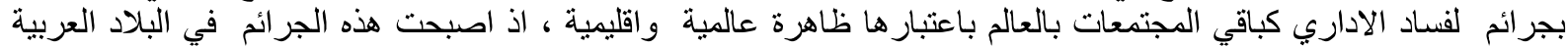

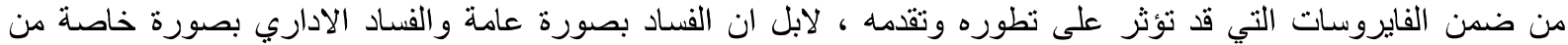

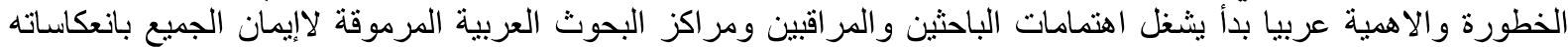

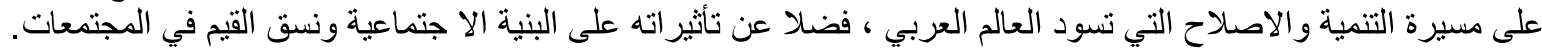

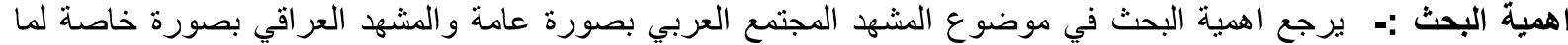

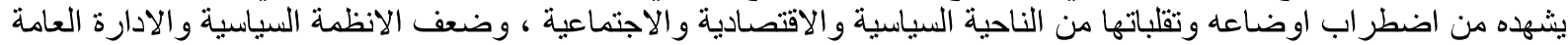

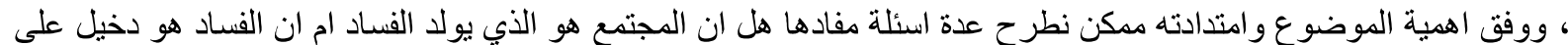

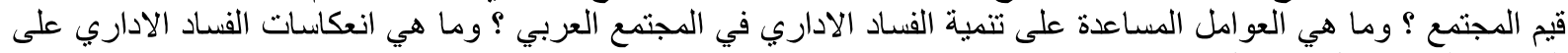

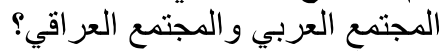

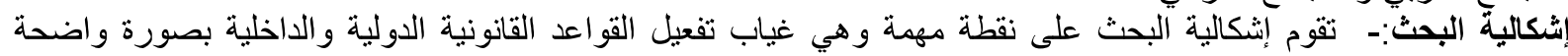

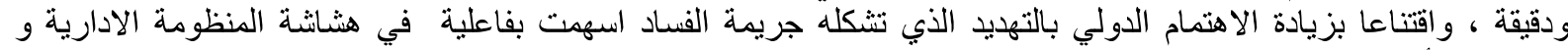

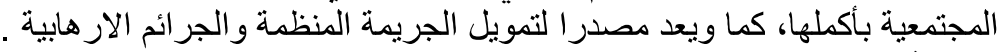

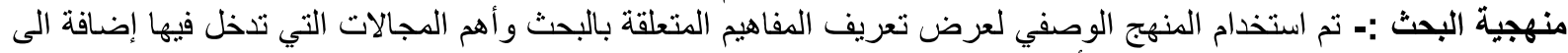

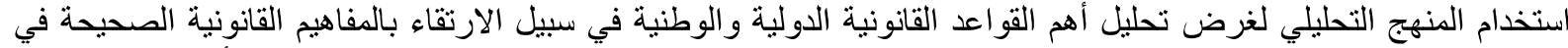

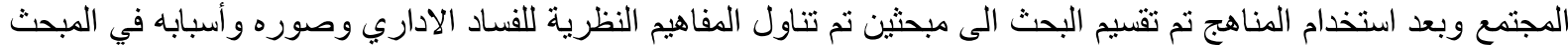

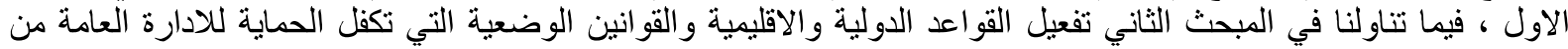

الاعتداء.

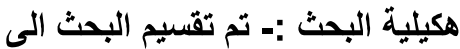

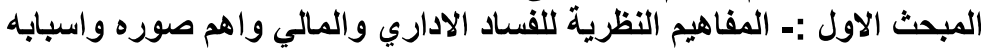

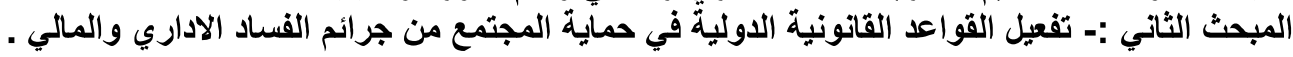

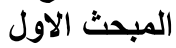

\section{مفهوم الفساد الاداري وصوره واسببابه}

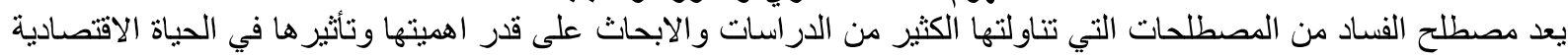

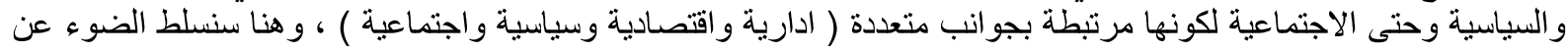
تعريف ظاهرة الفساد واهم صوره والاسباب التهاب التي ولدت هذه الظاهرة .

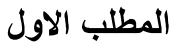

\section{مفهوم الفساد الاداري}

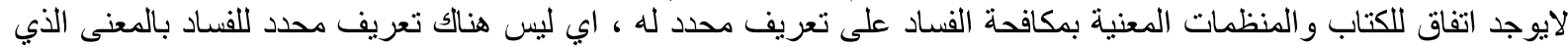

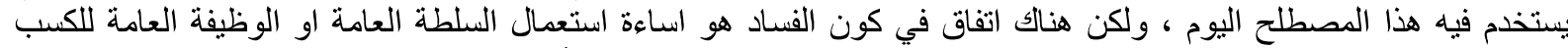

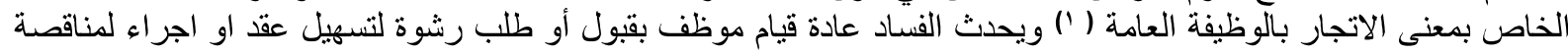

(1) فـارس بن علوش بن بـادي : دور الثفافية و المسـاءلة في الحد من الفساد الاداري في القطاعـات الحكومية ، اطروحة دكتور اه مقدمة الى جامعة نسايف

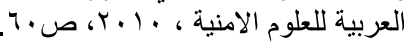




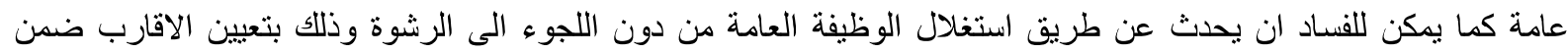

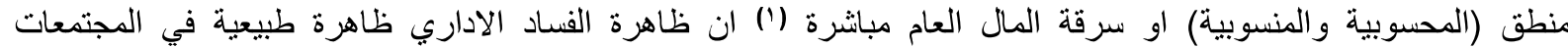

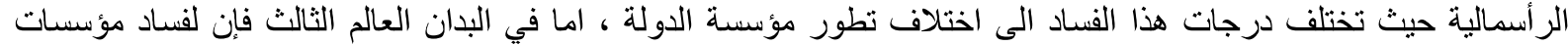

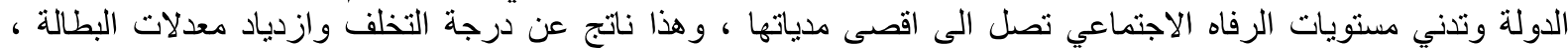

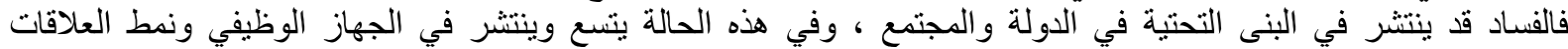

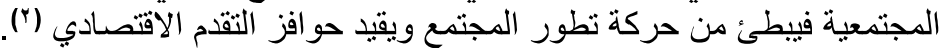

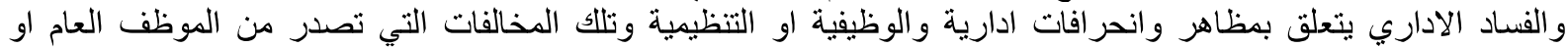

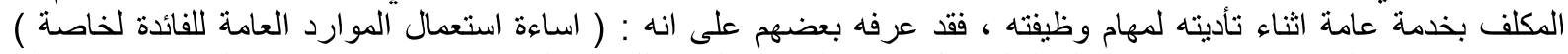

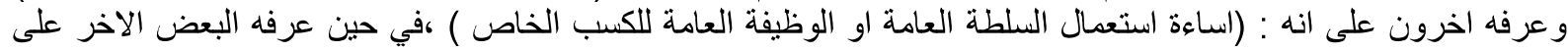

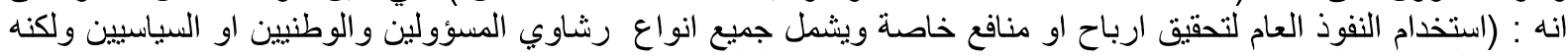

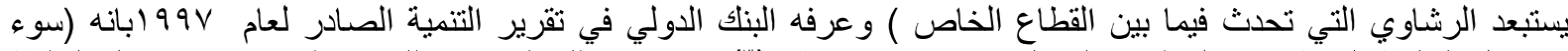

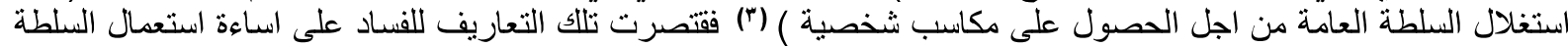

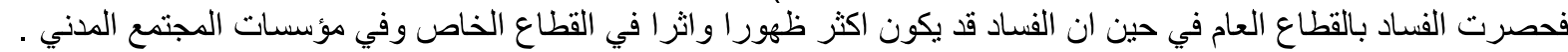

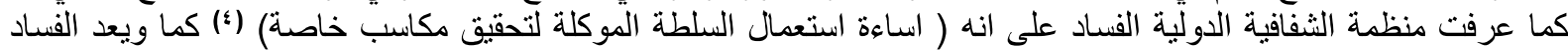

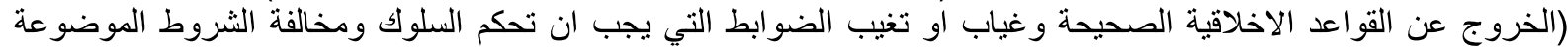

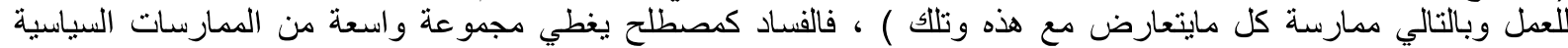
و الاقتصادية والادارية المشبوهة والمريبة وهنالك مجموعة من السلوكيات التي تعبر عن ظاهرة الفساد وهي منثابهة ومنداخلة في

وكثير من الاحيان (0).

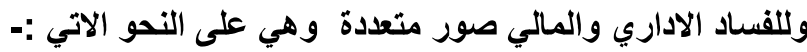

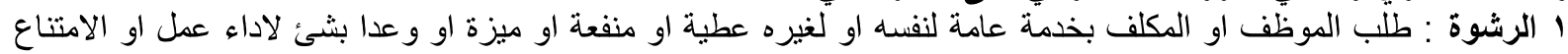

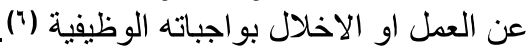

r- المحسوبية : تفضيل جهة على العه اخرى في الخدمة بغير حق للحصول على مصالح معينة ، وهي تنفيذ عمل مخالف للقانون

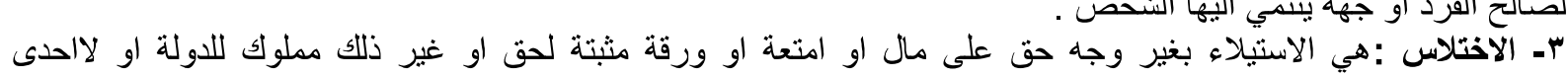

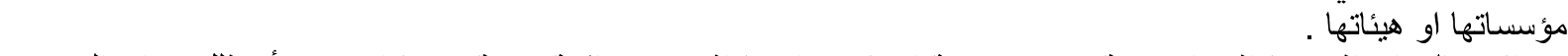

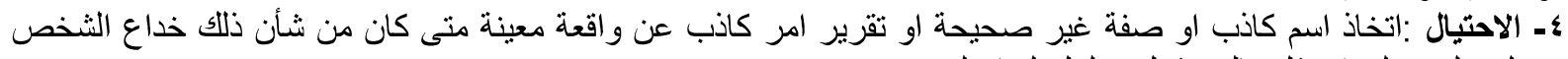

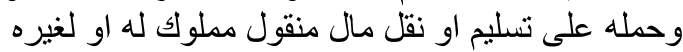

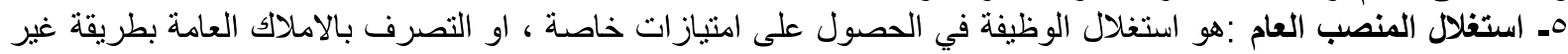

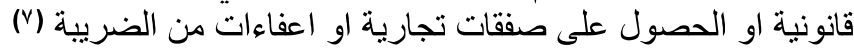
المطانب الثاني

اسباب الفساد الاداري والمباني والمبالي

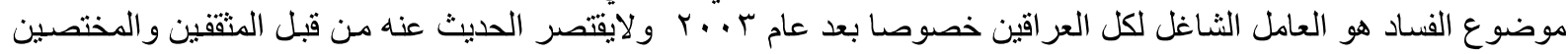

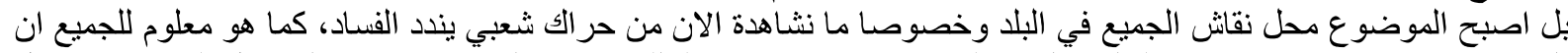

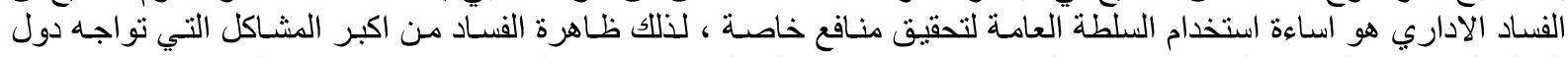

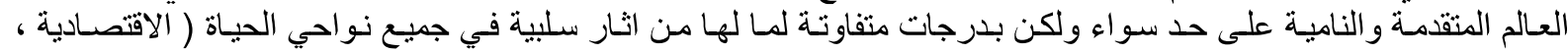

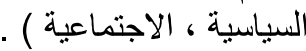

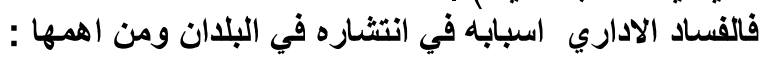

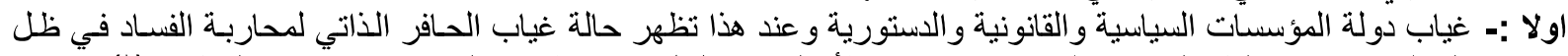

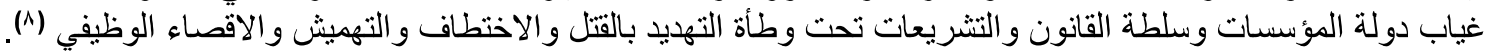

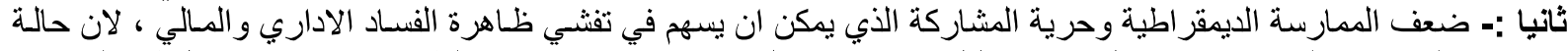

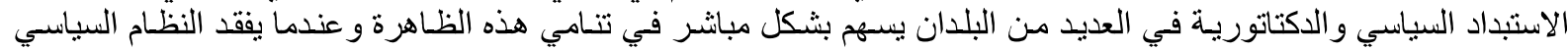

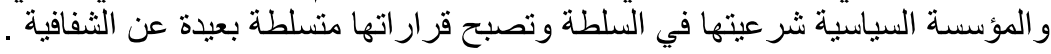

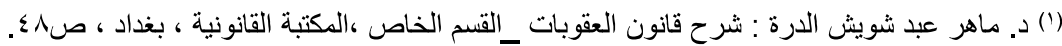

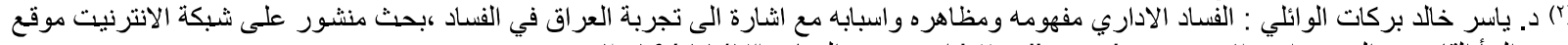

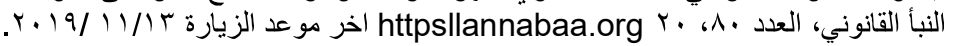

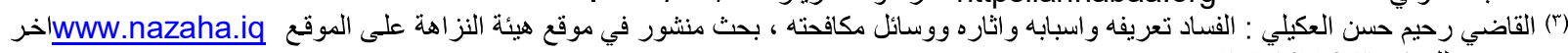

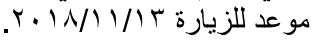

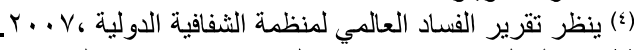

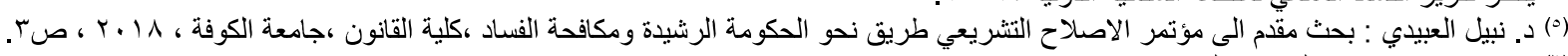

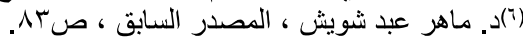

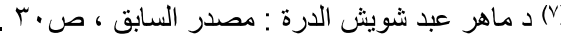

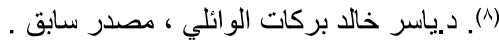




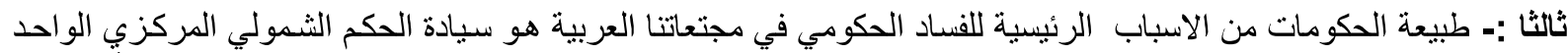

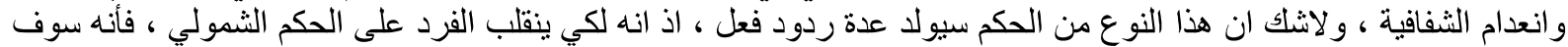

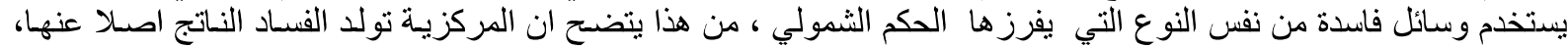

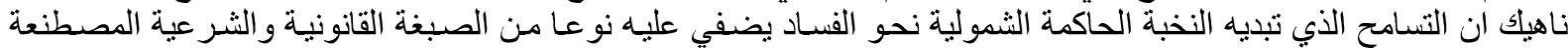

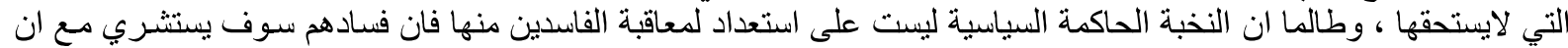

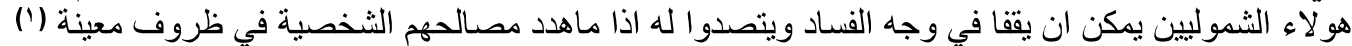

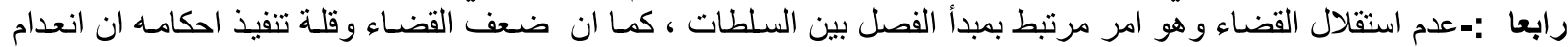

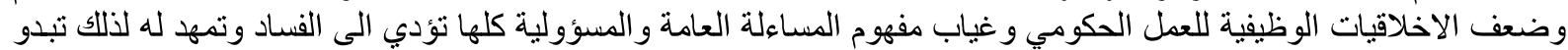

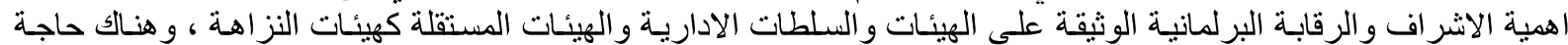

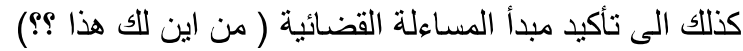

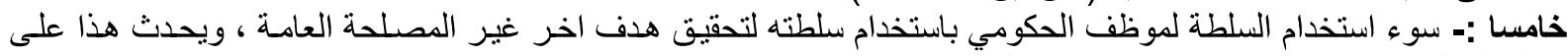

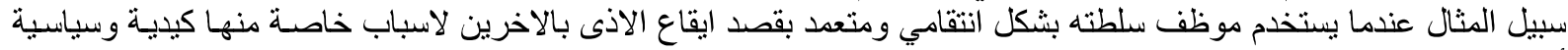

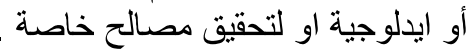

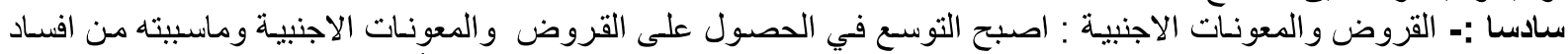

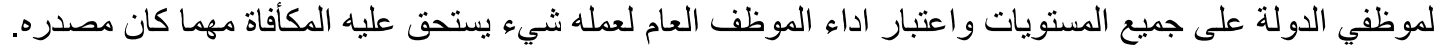

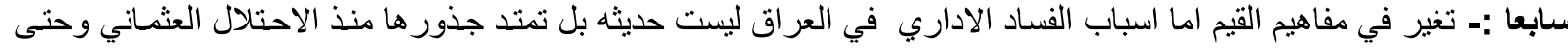

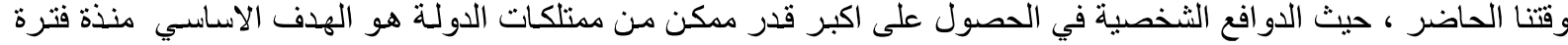

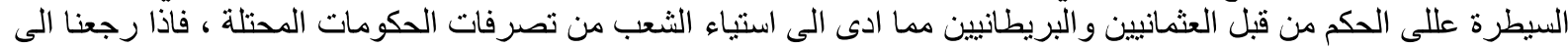

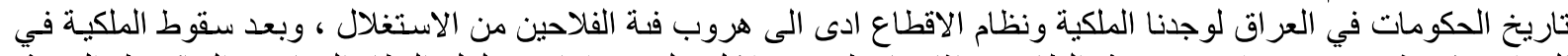

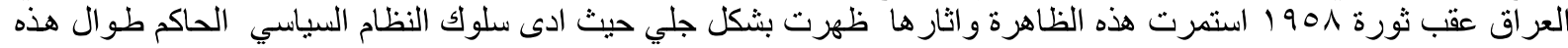

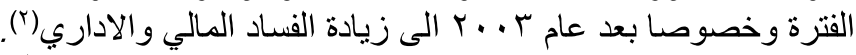
المبحث الثثاني

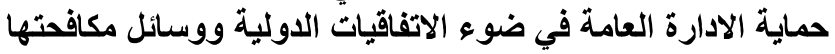

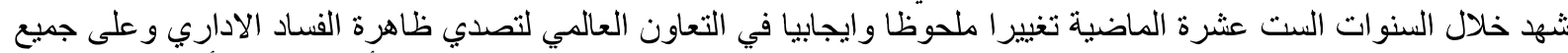

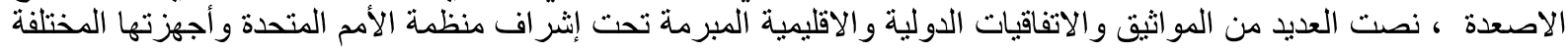

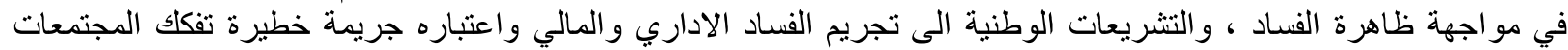

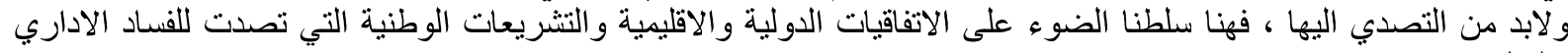

\section{المطلب الاول الاول}

و والمالي .

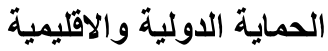

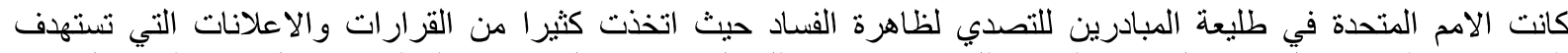

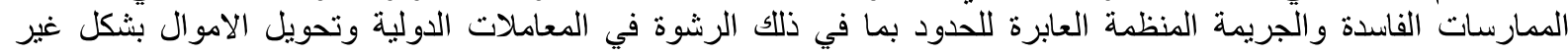

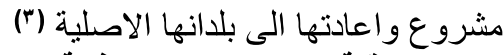

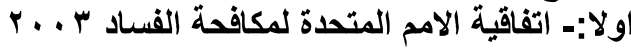

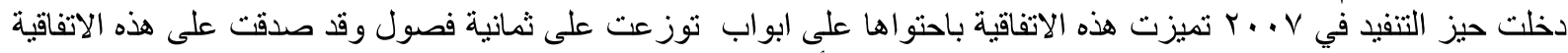

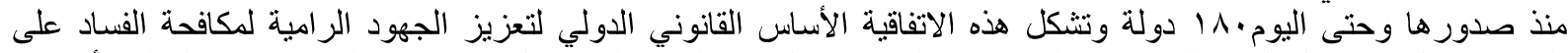

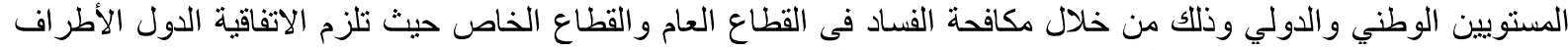

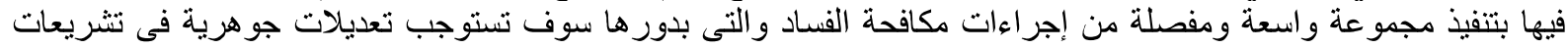

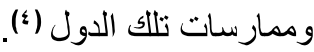

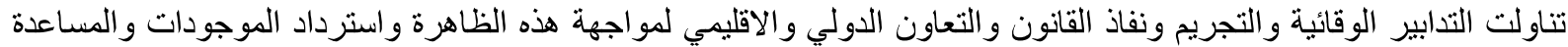

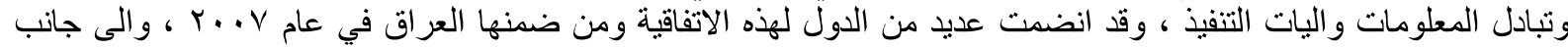

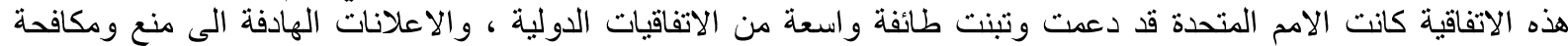

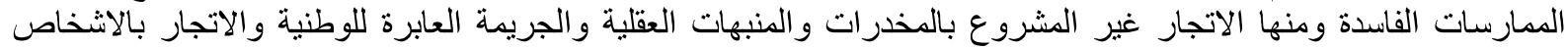

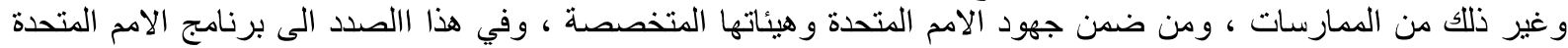

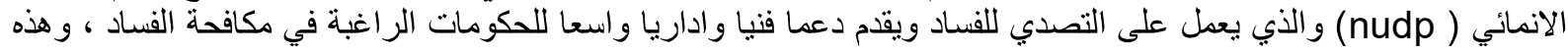

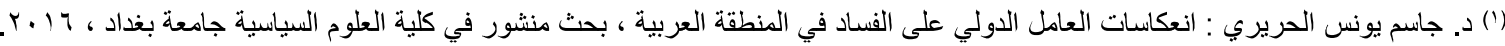

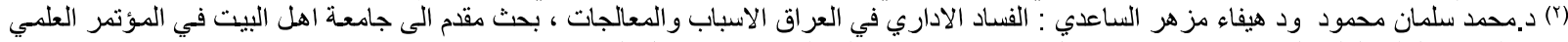

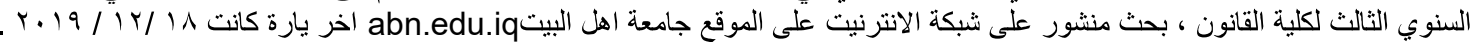

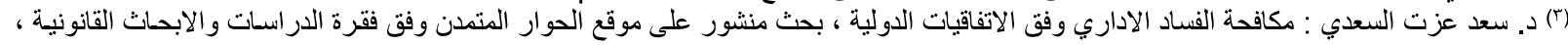

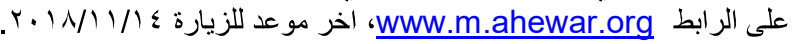

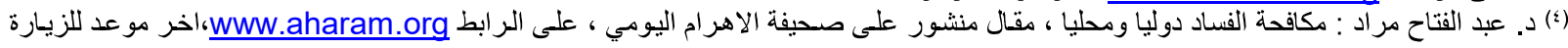




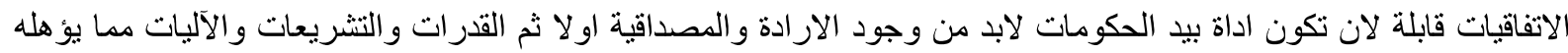

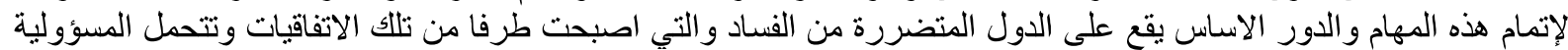

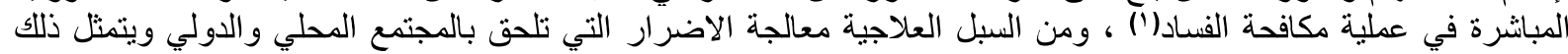

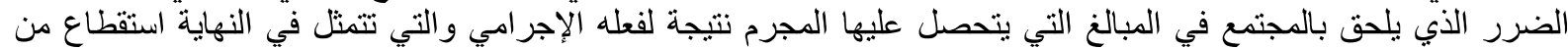

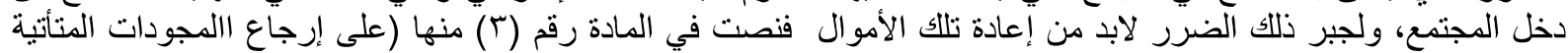

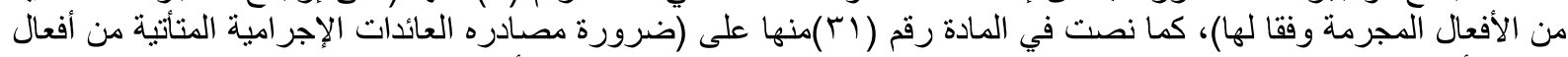

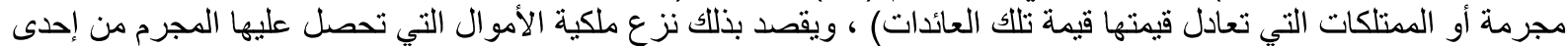

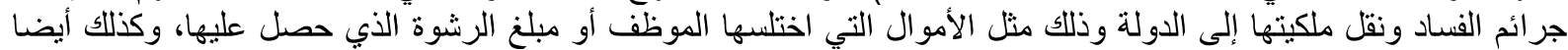

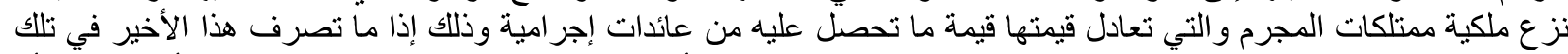

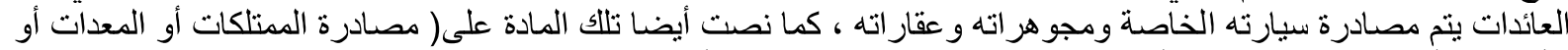

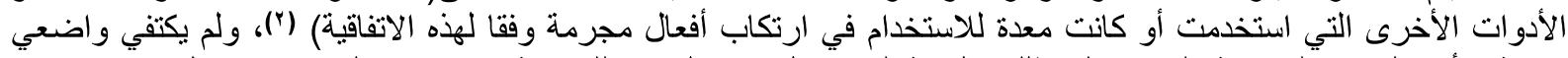

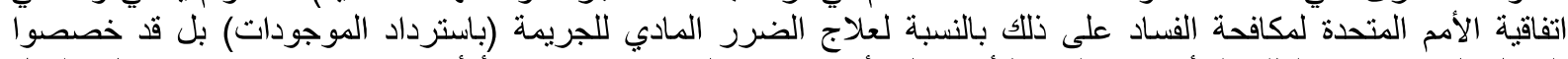

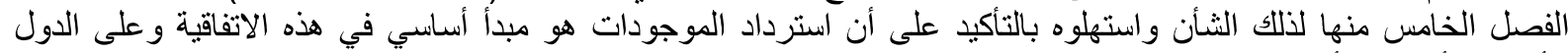

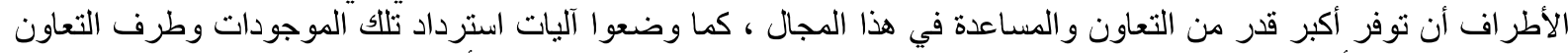

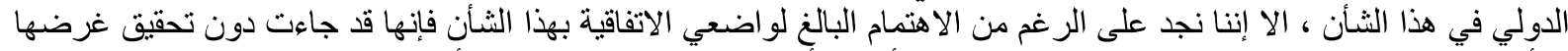

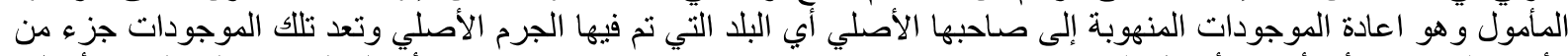

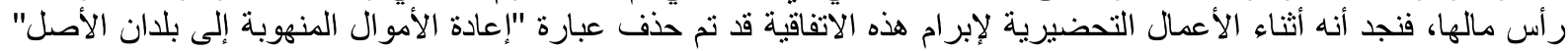

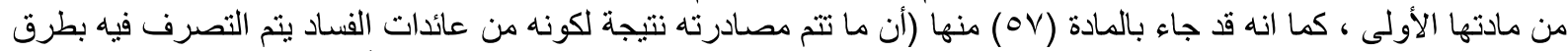

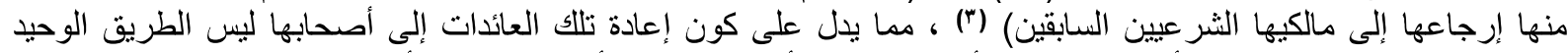

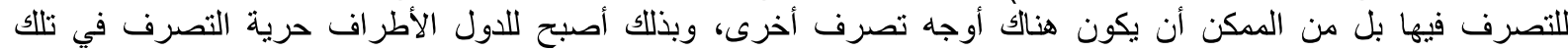

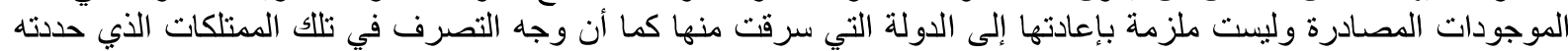

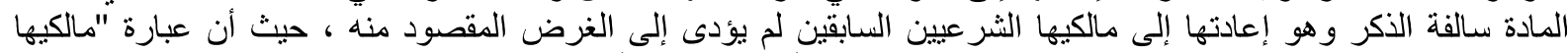

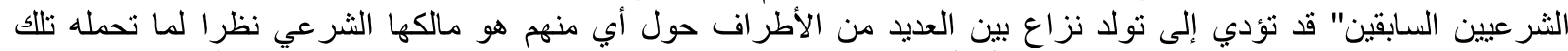

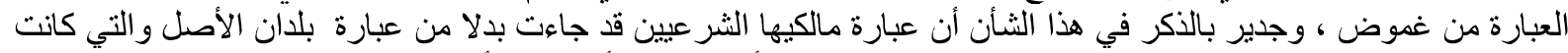

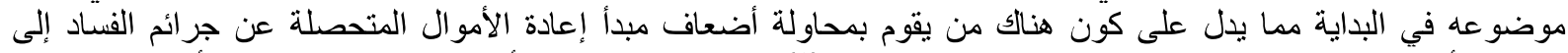

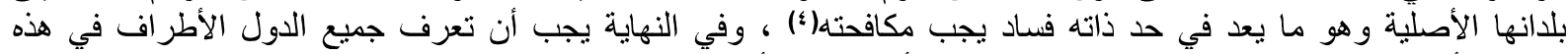

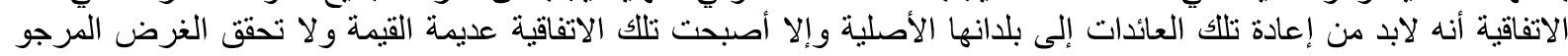

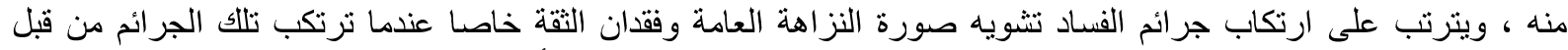

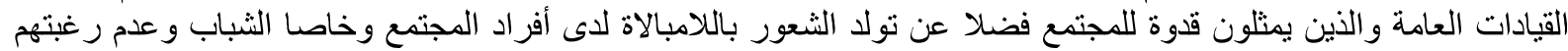

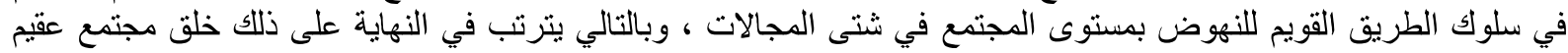

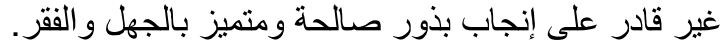

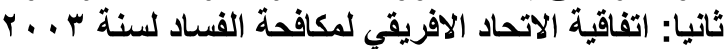

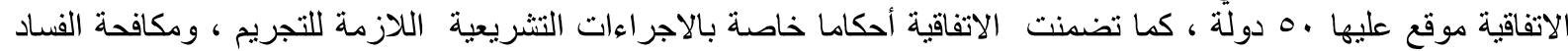

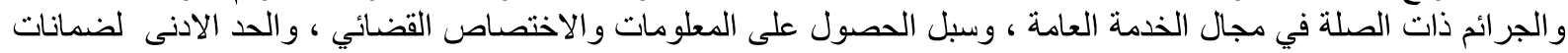

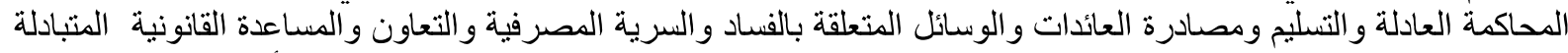

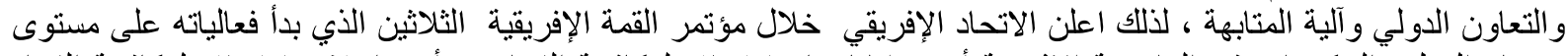

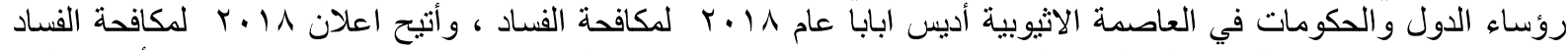
وإطلاقها فرصة مناسبة للبناء على التقدم المنجز حتى الان وتقييم الاحتياجات والتفكير في استراتيجيات جديدة من شأنها معالجة التهان

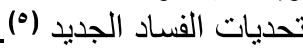

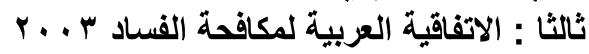

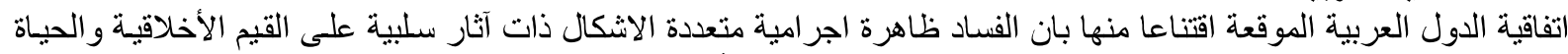

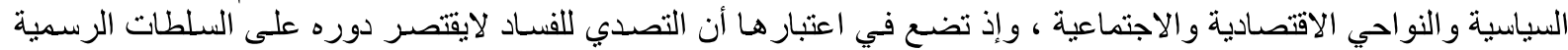

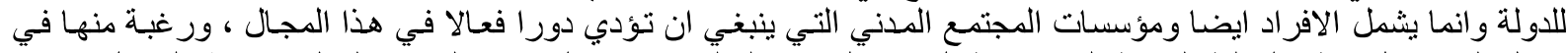

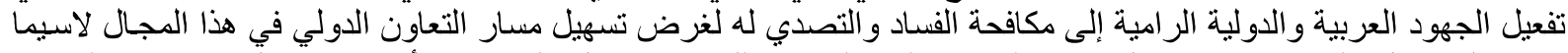

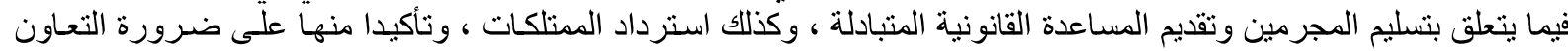

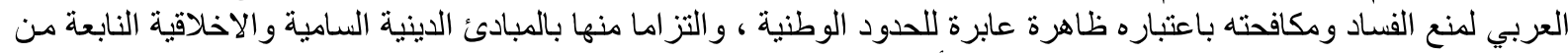

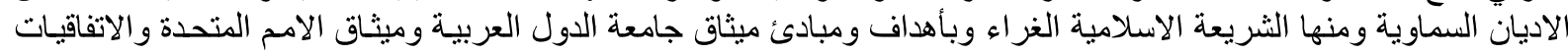

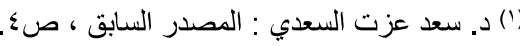

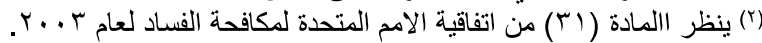

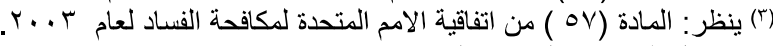

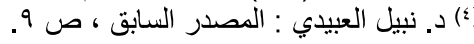

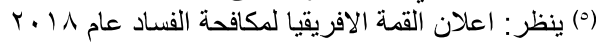




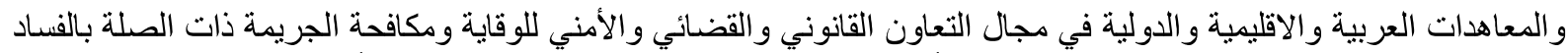

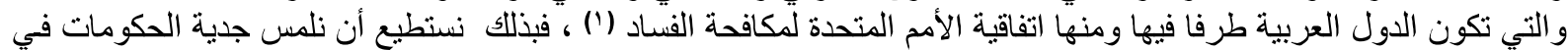

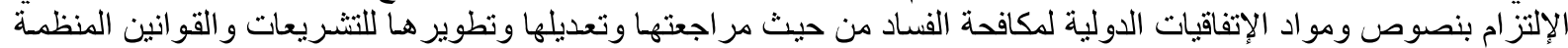

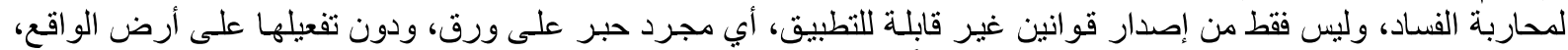

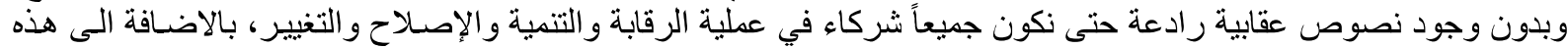

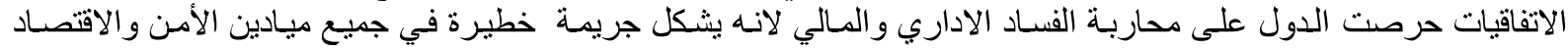

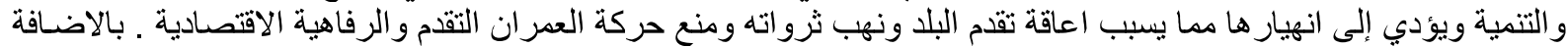

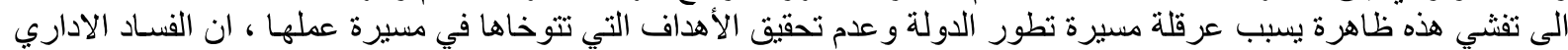

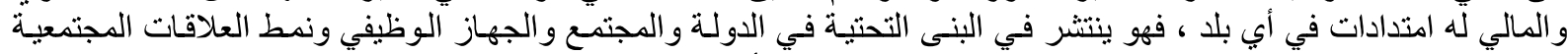

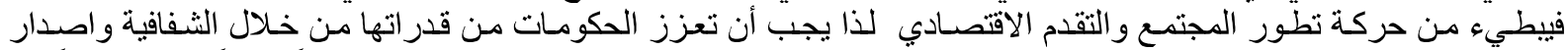

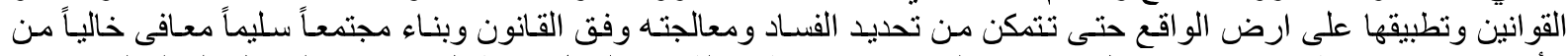

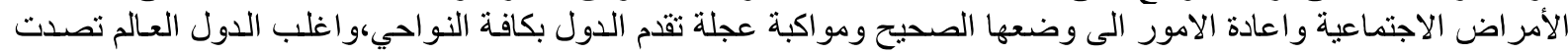

\section{المطلب الثاني \\ وسائل التصدي للفساد الاداري}

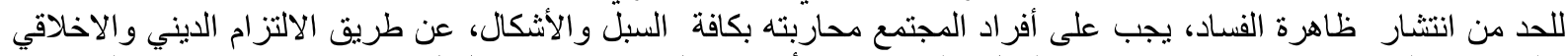

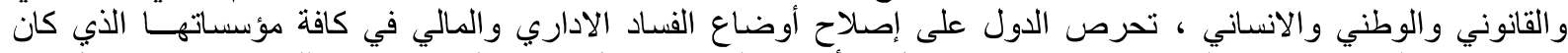

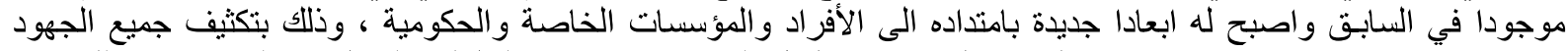

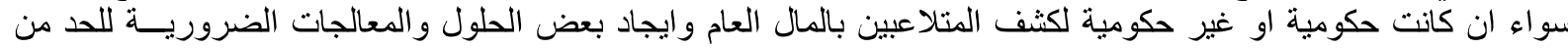

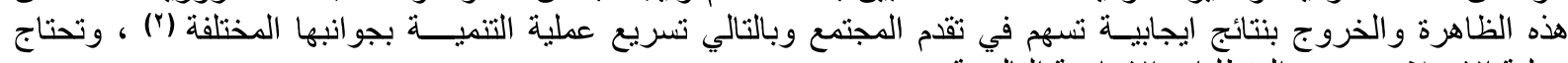

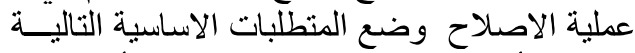

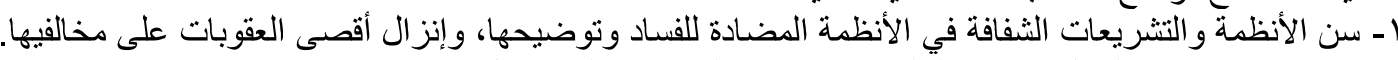

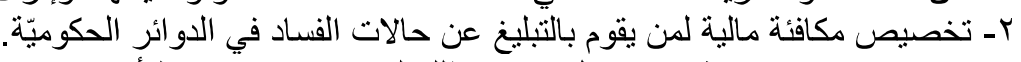

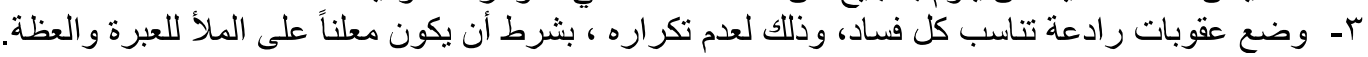

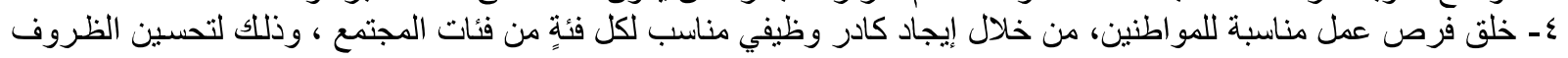

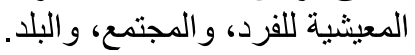

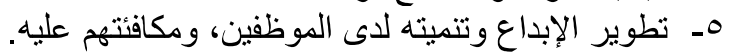

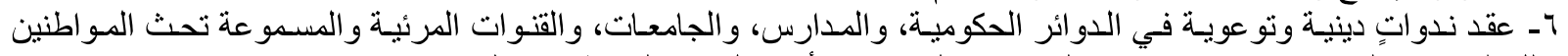

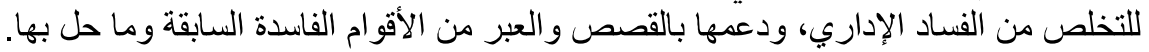

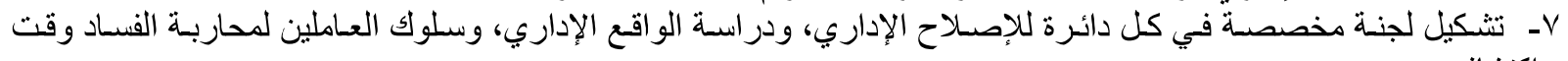

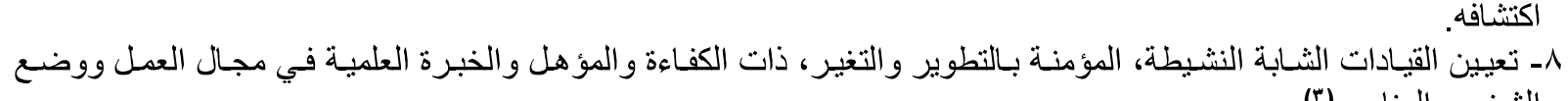

\section{الخاتمة}

الثخص المناسب(")

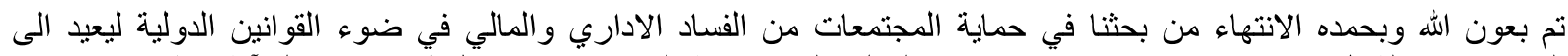

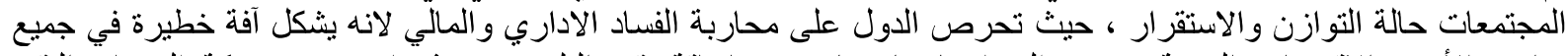

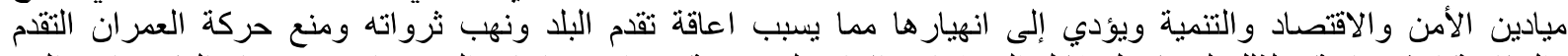

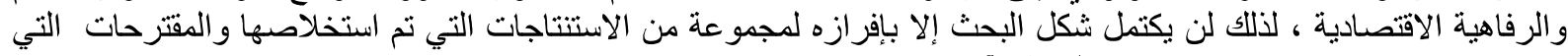

\section{الاستنتاجات}

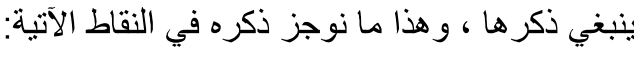

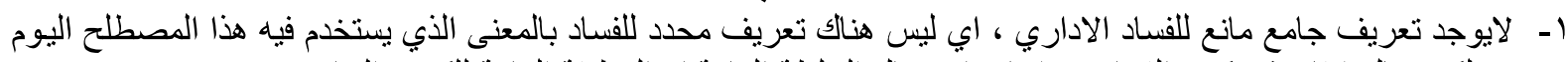

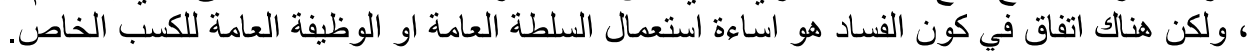

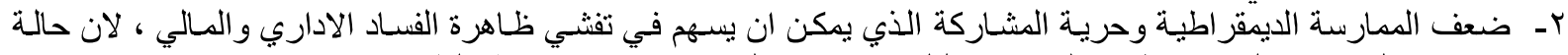

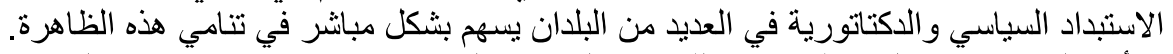

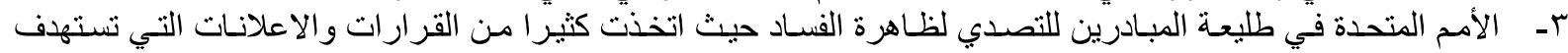

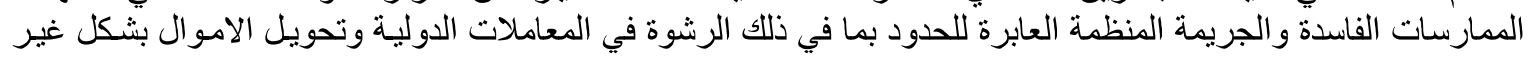
مشروع و اعادتها الى بلدانها الاصلية.

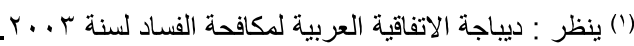

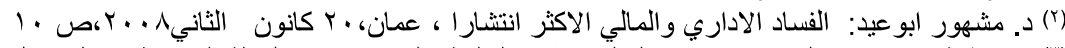

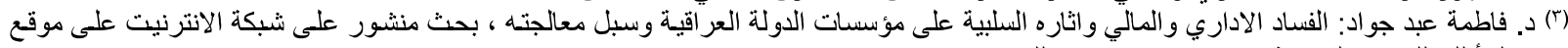

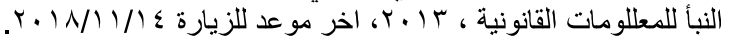


ع- - الدول العربية الموقعة على الاتفاقية العربية لمكافحة الفساد واقتناعا منها بأن الفساد ظاهرة اجرامية متعددة الاشكال لـه آثار

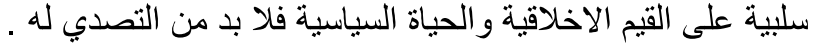

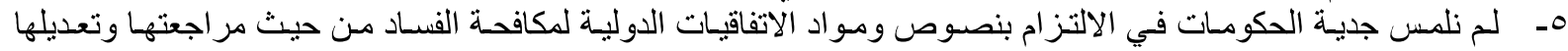

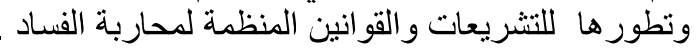

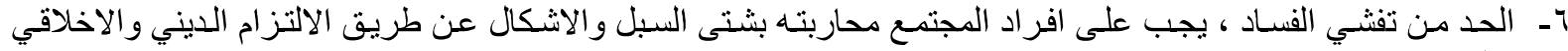

\section{التوصيات}

والوطني و الانساني.

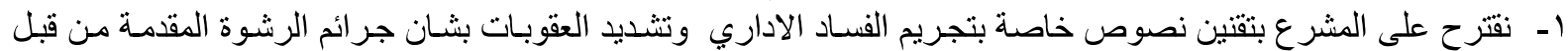

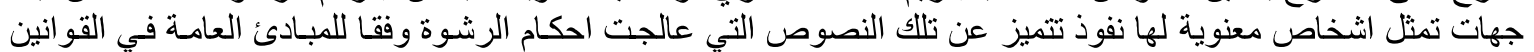

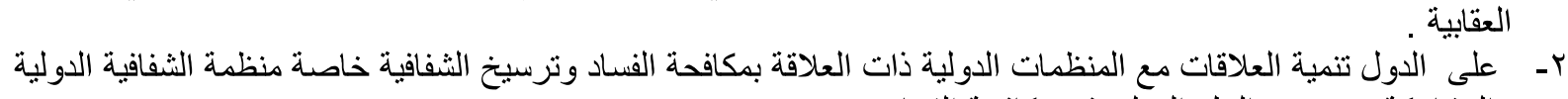

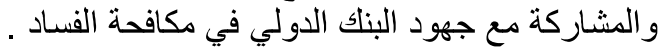

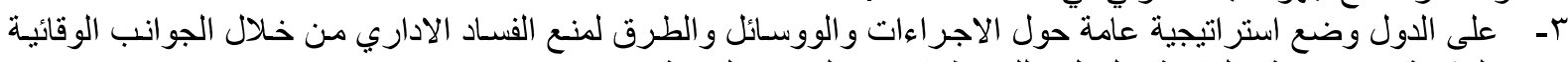

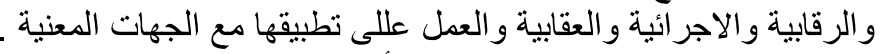

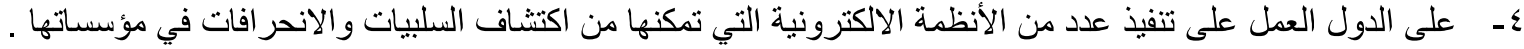

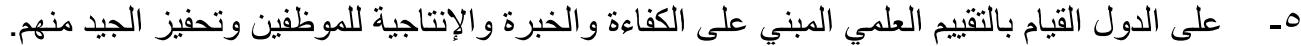

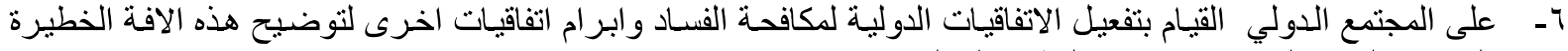
المصادر والقضاء عليها دوليا خصوصا بعد التطور التكنلوجي.

اولا:- الكتب العامة

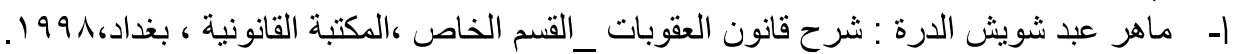

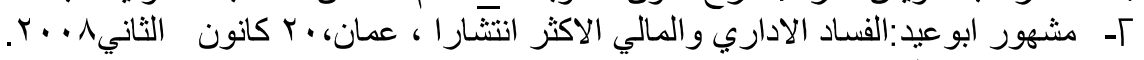

ثانيا :- الرسائل والاطاريح

ا- فارس بن علوش بن بالع بادي : دور الثفافية والمساءلة في الحد من الفساد الاداري في القطاعات الحكومية ، اطروحة

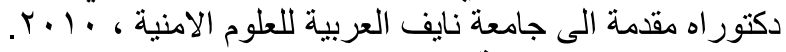

ثالثا:- البحوث والمجلات الاورية

اـ القاضئي رحيم حسن العكيلي :الفساد تعريفه واسبابه واثاره ووسائل مكافحته : بحث منشور في موقع هيئة النزاهة على

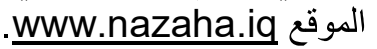

r- جاسم يونس الحريري : انعكاسات العامل الدولي على الفساد في المنطقة العربية ، بحث منشور في كلية العلوم السياسية

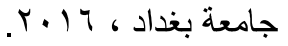

r- سعد عزت السعدي : مكافحة الفساد الاداري وفق الاتفاقيات الدولية ، بحث منشور على موقع الحوار المتمدن وفق فقرة

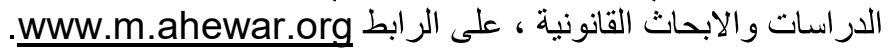

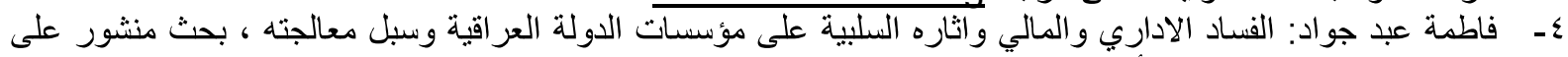

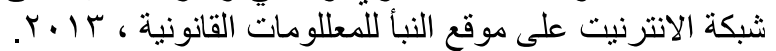

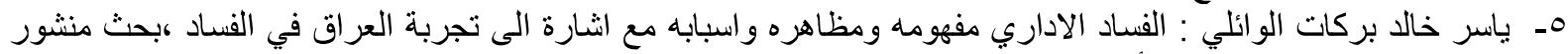

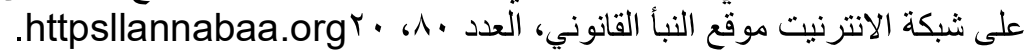

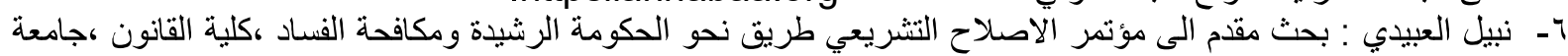

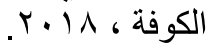

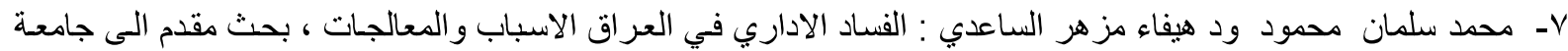

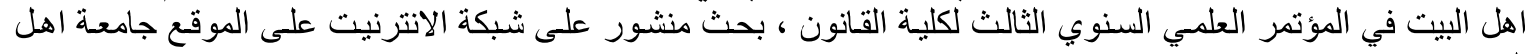

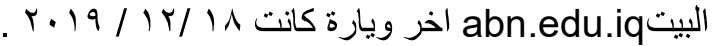

رابعا :- الاتفاقيات الدولية والاقليمية الإية

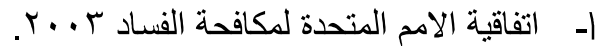

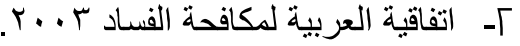

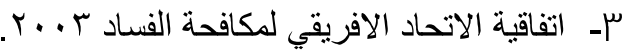

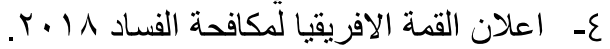

خامسا :- المصادر الالكترونية

ا- عبد الفتاح مر اد : مكافحة الفساد دوليا ومحليا ، مقال منشور على صحيفة الاهر ام اليومي ، على الر ابط

المستخلص مانص

.www.aharam.org

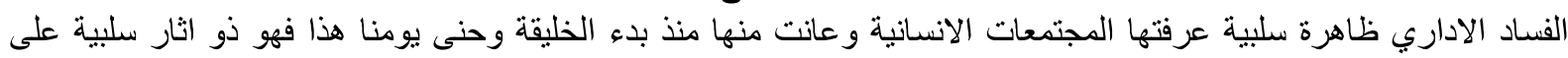

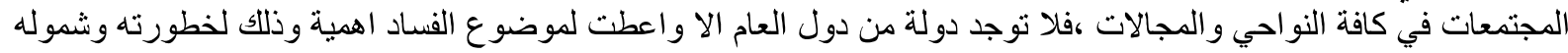




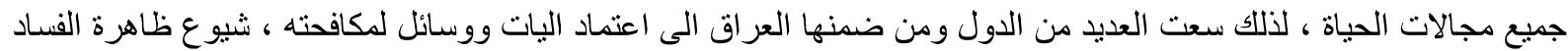

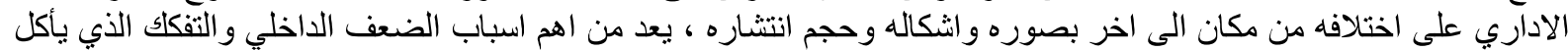

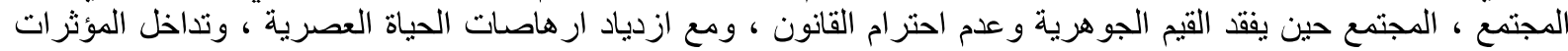

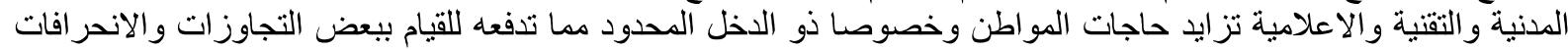

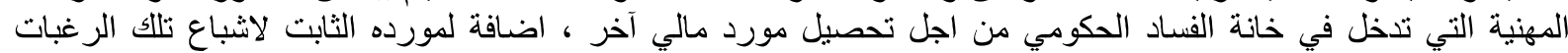

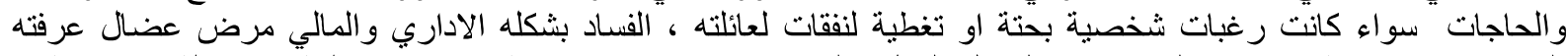

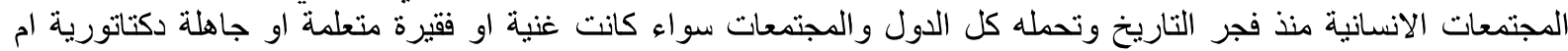

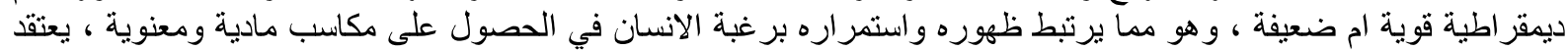

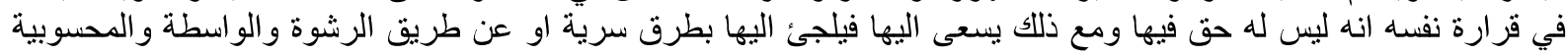

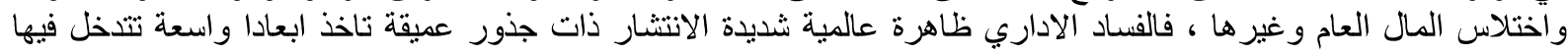

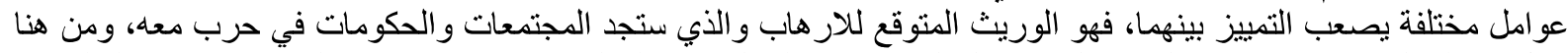

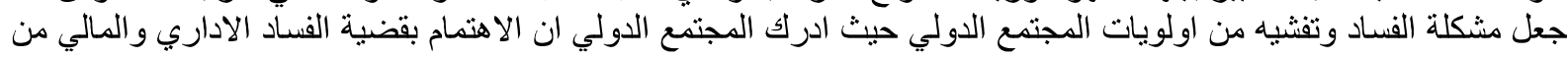

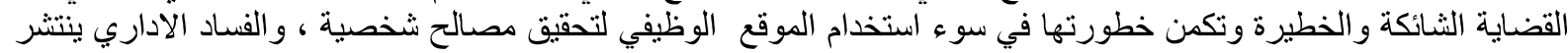

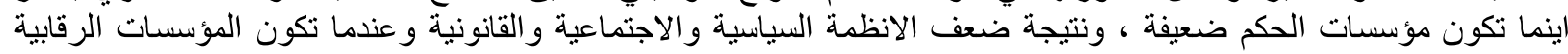

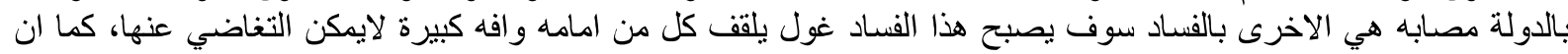

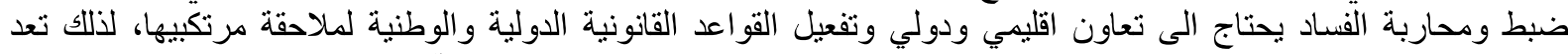

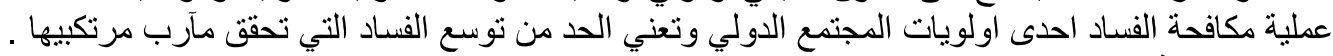

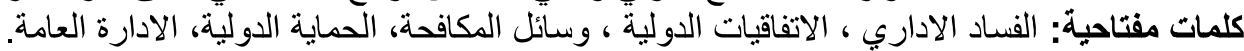

\section{Abstract}

The proliferation of the Administrative corruption phenomenon in all its forms sizes and places is considered one of the main reasons of the internal weakness and deterioration that affects society when society loses essential values and disobeying laws The he increase of modern life needs and the effects of society and media technology increases the needs of the low income individuals which forces them to commit certain violations which can be considered as Government Corruptions for the sake of obtaining additional income plus the main salary to satisfy the needs weather personal or for covering family expenses.

Corruption both Administrative and Financial is considered a Chronic disease that has been known to societies since the dawn of mine affects all sort of societies weather rich or poor educated o $r$ otherwise dictated or democratic society, powerful or weak. It is connected to the needs of individuals for obtaining financial or moral gains where anindividualb believes that he/she has no right in the assegais nevertheless an individual is perusing to obtain it in malicious ways either by partnership and embezzle public funds. Administrative Corruption is a widely spread global issue with deep roots and take several dimensions affected by several fact ors which are hard to recognize is the expected inheritance of terror ism which Societies and governments find themselves in a war with.

For this reason, the International Community has made it a priority to resolve this issue and consider it a dangerous one to be handled with. Its risk lies within achieve personal gains.

The administrative corruption thrives where the ruling government institutions are weak and the result of the fragility of the political social and legal systems.

When the monitoring institutions are corruption than corruption will be unstoppable thus should not be ignored.

Containing and neutralizing corruption needs regional and international cooperation and activating International and national laws in order to apprehend violators Combating corruption is considered on the priorities of the international community and to limit its expansion and stop those who commit corruption.

Keywords: the Administrative corruption, international conventions, means of confrontation, international protection, Public Administration. 